\title{
Relationship between reactive oxygen species production in human semen and sperm DNA damage assessed by Sperm Chromatin Structure Assay
}

\author{
Jiri Novotnya , Nabil Aziz ${ }^{b}$, Roman Rybarc, Jana Brezinovad ${ }^{d}$,Vera Kopeckae , Radka Filipcikovad ${ }^{d}$ Marie Reruchovaa , \\ Ivana Oborna ${ }^{f}$
}

\begin{abstract}
Aim. The aim of this prospective study was to find possible relationship between ROS production measured by chemiluminescence and flow cytometry in human semen and sperm DNA damage estimated by Sperm Chromatin Structure Assay.

Methods. Study included 39 men from infertile couples and 23 fertile volunteers who served as a control group. Aliquot of neat semen was used for ROS detection by chemiluminescence. Aliquot of sperm suspension in phosphate buffered saline was used for the detection of ROS by flow cytometry. Another aliquot of sperm suspension was used for SCSA to measure DNA fragmentation index and High DNA stainability.

Results. DNA fragmentation index correlated negatively with sperm morphology and motility. High DNA stainability correlated positively with ROS production and negatively with sperm morphology and concentration. Although there were similar trends of rising DNA fragmentation index and ROS production among the three groups of men, the relationship did not reach statistical significance.
\end{abstract}

Conclusions. Higher values of DNA fragmentation index and high DNA stainability may also reflect developmental and/or environmental problems and not only oxidative stress.

Key words: human semen, ROS, SCSA, DNA damage

Received: February 14, 2013; Accepted with revision: August 29, 2013; Available online: September 27, 2013

http://dx.doi.org/10.5507/bp.2013.065

${ }^{a}$ Department of Biology, Faculty of Medicine and Dentistry, Palacky University Olomouc, Czech Republic

${ }^{b}$ Gynaecology and Reproductive Medicine, Liverpool Women's Hospital and the University of Liverpool, Merseyside, United Kingdom

'Centre of Assisted Reproduction SANUS Jihlava, Czech Republic

${ }^{d}$ Department of Anatomy, Faculty of Medicine and Dentistry, Palacky University Olomouc

${ }^{e}$ Department of Genetics and Reproduction, Veterinary Research Institute, Brno

${ }^{f}$ Department of Obstetrics and Gynaecology, University Hospital Olomouc

Corresponding author: Ivana Oborna, e-mail:obornai@seznam.cz

\section{INTRODUCTION}

Sperm chromatin integrity is essential for the transmission of paternal genetic information. DNA damage also has significant negative impact on in vitro fertilization ${ }^{1}$. Infertile men have been found to have substantially higher sperm DNA damage than fertile men ${ }^{1-3}$. In addition, numerous studies reported significant, negative correlations between sperm DNA damage and the outcome of assisted reproductive technologies (ART). However, this view is not universally supported ${ }^{4}$. Sperm DNA damage may occur at any of the stages of spermatogenesis. At least three molecular mechanisms are suggested to cause sperm DNA damage: (i) alterations of sperm chromatin packaging ${ }^{5,6}$, (ii) aborted apoptosis ${ }^{1,15}$ and (iii) oxidative stress. Reactive oxygen species (ROS) produced in small amounts are necessary for sperm functions such as capacitation and acrosome reaction ${ }^{8}$. Excessive ROS production however is negatively linked to sperm function and morphology $y^{9-14}$ and may be secondary to urogenital tract infections, neutrophils and macrophages infiltration ${ }^{15}$, radiation, chemotherapy and smoking.
The aim of our study was to compare levels of ROS production in human semen measured by chemiluminescence and flow cytometry with the levels of sperm DNA damage estimated by SCSA.

\section{MATERIALS AND METHODS}

The study was approved by the Ethics Board of the Palacky University in Olomouc, Czech Republic. All assessed males were healthy non-smokers without any dietary restrictions and signed the written consent. The study sample included 23 volunteers with proven natural fertility and sperm donors (control group) and 39 men from couples suffering from infertility who were divided into two groups: 16 normozoospermic males (NSI group) and 23 males with semen abnormalities (SA group).

\section{Semen collection and analysis}

Semen samples were collected by masturbation after a period of 3 to 5 days of sexual abstinence. After liquefaction $\left(37^{\circ} \mathrm{C}, 30 \mathrm{~min}\right)$, standard semen analysis was 
performed according to WHO 2010 guidelines ${ }^{16}$. Aliquot of liquefied semen sample $(400 \mu \mathrm{L})$ was used for direct ROS estimation in neat semen by chemiluminescent (CL) assay. Another aliquot of liquefied semen $(500 \mu \mathrm{L})$ was centrifuged at $300 \times \mathrm{g}$ for $7 \mathrm{~min}$. The peletted cells were resuspended in isotonic phosphate buffered saline (PBS) and sperm concentration was adjusted to $1 \times 10^{6} / \mathrm{mL}$. One aliquot of this sperm suspension was immediately used for ROS detection by CL flow cytometry and another aliquot was used as a blank control. For SCSA assay, another aliquot was centrifuged and resuspended in TNE buffer (15 mmol L-1 $\mathrm{NaCl}, 10 \mathrm{mmol} \mathrm{L}-1$ Tris and $1 \mathrm{mmol} \mathrm{L}^{-1}$ EDTA, $\mathrm{pH}=6.8)$ and frozen in liquid nitrogen.

\section{ROS detection by CL assay}

ROS production was measured using luminol (5-amino-2, 3-dihydro-1, 4-phthalazinedione; Sigma Chemical Co., St. Louis, MO, USA) as a probe. Luminol $(10 \mu \mathrm{L}, 5$ mmol $\mathrm{L}^{-1}$ ) prepared in dimethylsulphoxide (DMSO) was added to $400 \mu \mathrm{L}$ of the neat semen and data were immediately recorded. Blank samples for estimation of background signal were prepared by pipetting $10 \mu \mathrm{L}$ of $5 \mathrm{mmol}$ $\mathrm{L}^{-1}$ luminol to $400 \mu \mathrm{L}$ of PBS. The chemiluminescent signal was monitored for 15 min using a Digene DCR-1 single tube luminometer (Digene Diagnostics, Inc., Gaithesburg, MD, USA). Results were expressed as relative light unit (RLU) per minute per $20 \times 10^{6}$ spermatozoa $^{17}$.

\section{ROS detection by flow cytometry}

Dihydrorhodamine 123 dye (DHR 123; Life Technologies Corporation Carlsbad, CA, USA) was used to detect ROS as previously described ${ }^{15}$. DHR123 $(1 \mu \mathrm{L}$,
$1 \mathrm{mmol} \mathrm{L}^{-1}$ solution in DMSO) was added to $1 \mathrm{~mL}$ aliquot of sperm suspension containing $1 \times 10^{6}$ spermatozoa and incubated at $37^{\circ} \mathrm{C}$ for $20 \mathrm{~min}$. Unstained aliquot of each sperm sample was used as a blank control to estimate autofluorescence background. Flow cytometer FACS Calibur (BD Biosciences, San Jose, CA, USA) was used and data were analyzed using BD CellQuestPro software (BD Biosciences, San Jose, CA, USA). 25,000 cells were analyzed in each sample. Flow cytometric results were expressed in relative fluorescence unit (RFU) per $20 \times 10^{3}$ spermatozoa $^{15}$.

\section{Sperm chromatin structure assay (SCSA)}

Sperm DNA damage was assessed by the SCSA as previously described ${ }^{2}$. Frozen samples were rapidly thawed in a $37{ }^{\circ} \mathrm{C}$ water bath and $200 \mu \mathrm{L}$ of sample was treated with $400 \mu \mathrm{L}$ acidic detergent solution $\left(80 \mathrm{mmol} \mathrm{L}^{-1} \mathrm{HCl}\right.$, $0.1 \%$ Triton-X $100, \mathrm{pH}=1.2$ ) for exactly $30 \mathrm{~s}$ to induce DNA denaturation. Acridine Orange (AO) staining solution ( $1.2 \mathrm{~mL}, 6 \mu \mathrm{g} \mathrm{mL} \mathrm{m}^{-1}$ ) was added to sperm suspension. Flow cytometer FACS Calibur (BD Biosciences, San Jose, CA, USA) was used and data were analyzed using BD CellQuestPro software (BD Biosciences, San Jose, CA, USA). The extent of DNA denaturation was expressed in terms of DNA fragmentation index (DFI) and the abnormally high DNA stainability (HDS) using SCSASoft software (SCSA ${ }^{\circledR}$ DIAGNOSTICS, INC, Brookings Research \& Technology Center, Brookings, SD, USA). 5,000 cells were analyzed in each sample. Duplicate measurements were performed; the sample for duplicate measurement was taken from the same thawed aliquot, diluted appropriately, processed for the SCSA and measured.

Table 1. Semen parameters and ROS production.

\begin{tabular}{|c|c|c|c|c|}
\hline \multirow[b]{2}{*}{ Parameter } & \multicolumn{3}{|c|}{ Study groups } & \multirow[b]{2}{*}{$P$ values } \\
\hline & $\begin{array}{l}\text { control group } \\
(\mathrm{n}=23)\end{array}$ & $\begin{array}{l}\text { NSI } \\
(n=16)\end{array}$ & $\begin{array}{l}\text { SA } \\
(n=23)\end{array}$ & \\
\hline Age (years) & $32(29,35)$ & $34(29,38)$ & $34(30,39)$ & N.S \\
\hline $\begin{array}{l}\text { Sperm concentration } \\
\left(10^{6} \text { sperm } / \mathrm{mL}\right)\end{array}$ & $65(37 ; 78)^{a}$ & $41(26 ; 65)^{b}$ & $10(5 ; 19)^{\mathrm{a}, \mathrm{b}}$ & a: $P<10^{-6}$, b: $P<0.002$ \\
\hline $\begin{array}{l}\text { Sperm normal morphology } \\
(\%)\end{array}$ & $35(30.5 ; 40)^{\mathrm{a}}$ & $31.5(30.5 ; 33.5)^{\mathrm{b}}$ & $17(8.5 ; 24)^{\mathrm{a}, \mathrm{b}}$ & a: $P<10^{-6}$, b: $P<2.5 \times 10^{-4}$ \\
\hline $\begin{array}{l}\text { Sperm motility } \\
(\%)\end{array}$ & $56(43.5 ; 61.5)$ & $51(44 ; 55)$ & $50(34.5 ; 57.5)$ & N.S \\
\hline $\begin{array}{l}\text { CL } \\
\left(\log \mathrm{RLU} / \mathrm{min} / 20 \times 10^{6} \text { sperm }\right)\end{array}$ & $2.92(2.32 ; 3.60)^{a, b}$ & $3.78(3.09 ; 4.40)^{\mathrm{a}}$ & $4.02(3.79 ; 4.29)^{b}$ & a: $P<0.05$, b: $P<1.5 \times 10^{-4}$ \\
\hline $\begin{array}{l}\text { DHR123 } \\
\left(\log \text { RFU } / 20 \times 10^{3} \text { sperm }\right)\end{array}$ & $4.86(4.78 ; 5.28)$ & $4.97(4.85 ; 5.22)$ & $5.20(4.81 ; 5.34)$ & N.S \\
\hline $\begin{array}{l}\text { Sperm DFI } \\
(\%)\end{array}$ & $16.5(11.5 ; 27.7)^{\mathrm{a}}$ & $22.6(11.8 ; 42.3)$ & $35.0(24.8 ; 41,3)^{\mathrm{a}}$ & a: $P<0.0035$ \\
\hline $\begin{array}{l}\text { High DNA stainability } \\
(\%)\end{array}$ & $12.1(8.4 ; 17.9)^{\mathrm{a}}$ & $12.4(10.3 ; 17.1)^{\mathrm{b}}$ & $24.4(14.8 ; 31.6)^{a, b}$ & a: $P<0.007,{ }^{\text {b: }} P<0.035$ \\
\hline
\end{tabular}

Legend: Data are expressed as medians $\left(25^{\text {th }}, 75^{\text {th }}\right.$ percentiles $)$. Kruskal-Wallis test was used to compare sperm variables among the three groups. Letters ${ }^{\mathrm{a}}$ and ${ }^{\mathrm{b}}$ mark significant differences in evaluated parameters between groups. 


\section{Statistical analysis}

Summary statistics are presented as median $\left(25^{\text {th }}\right.$ and $75^{\text {th }}$ percentiles). Kruskal-Wallis test was used to compare sperm variables among the three groups. Spearman's rank correlation was used to test the relationship between ROS production and DNA damage and between semen parameters and sperm DNA damage. All hypotheses testing was two-tailed; $P<0.05$ was considered to be statistically significant. All statistical analyses were performed using software Statistica 8 (StatSoft, Inc.).

\section{RESULTS}

The median $\left(25^{\text {th }}\right.$ and $75^{\text {th }}$ percentiles $)$ of age, semen parameters and ROS production in the three groups are given in Table 1. Sperm concentration and percentage normal sperm morphology were significantly lower in both SA and NSI groups compared to control group. Sperm motility was not significantly different among all three groups.

The median ROS production estimated by CL assay was lowest in the control group and highest for the SA group. The difference between the three groups was significant (Table 1). There was also a similar trend of progressively higher median of ROS production estimated by DHR123 from control group to NSI group to SA group (4.86, 4.97 and 5.20, respectively). However, the difference between groups was not significant. The median DFI \% was lowest in the control group, non-significantly higher in NSI group and significantly higher in SA group $(P<0.0035)$. High DNA stainability was found to be significantly higher in SA group than in control group $(P<0.007)$ and in NSI group than in control group $(P<0.035)$.

\section{Association between DNA damage and ROS production}

DFI did not correlate with any measure of ROS production ( $r=0.04$ for CL assay and $r=-0.04$ for DHR123). High DNA stainability correlated positively with ROS production estimated by $\mathrm{CL}$ assay $(r=0.27, P<0.03)$ and DHR123 $(r=0.27, P<0.041)$.

\section{Association between DNA damage and standard semen parameters}

Sperm DNA fragmentation correlated negatively with normal sperm morphology $(\mathrm{r}=-0.44, P<0.0004)$ and sperm motility $(r=-0.30, P<0.017)$. Correlation between sperm DNA fragmentation and sperm concentration was not significant $(\mathrm{r}=-0.23, P<0.071)$. High DNA stainability correlated negatively with normal sperm morphology $(r=$ -0.41, $P<0.0008)$ and concentration $\left(r=-0.60, P<10^{-6}\right)$. Correlation between high DNA stainability and sperm motility was not found $(r=-0.02)$.

\section{DISCUSSION}

Some authors have reported a positive correlation between ROS production and sperm DNA damage ${ }^{18,19}$. The results of our study demonstrated that there was a trend of rising DFI \%, from control group to NSI group to infertile group with abnormal semen parameters. There was also a similar trend of raising ROS production measured with the CL method and DHR123 in the same group order. However, the relationship between DFI and ROS production did not reach statistical significance. The magnitude of DNA fragmentation is influenced by a diversity of developmental (apoptosis), biological (varicocele, high prolonged fever, advanced age) and environmental (radiation, air pollution, smoking, pesticides, and chemicals) factors. Because of this multifactorial origin of DNA damage, some other studies that examined the relationship between other factors such as apoptosis and sperm DNA fragmentation failed to demonstrate a significant positive relationship ${ }^{20}$. In our study, there were even ejaculate samples showing high level of ROS production but negligible sperm DNA damage. On the other hand, there were also samples showing negligible ROS production but high percentage of spermatozoa with fragmented DNA. It was previously suggested that ROS measurement provided information about current status of ejaculate but it did not necessarily correspond with oxidative stress acting on spermatozoa during sperm maturation and its epididymal transit ${ }^{21}$.

Flow cytometry provides an estimate of ROS production in the intracellular space only, while CL assay provides a global estimate in both extracellular and intracellular space. Our study demonstrated stronger association between DFI and semen parameters than between DHR123 and semen parameters. This may be due to the inclusion of healthy fertile volunteers in our study population. Desai et al. demonstrated that reactive oxygen species levels are independent of sperm concentration, motility, and abstinence in a normal, healthy, proven fertile $\operatorname{man}^{22}$.

In our study, semen samples from males with semen abnormalities showed significantly higher values of both SCSA parameters (DFI and HDS) in comparison to control group (healthy, proven fertile men). This is in accordance with other studies ${ }^{1,2,3,22,23}$. We found significant negative correlations between DFI and sperm morphology as well as between DFI and sperm motility. Furthermore, we found significant negative correlations between HDS and sperm concentration as well as between HDS and sperm morphology. These results are in accordance with previous findings that spermatozoa from patients with abnormal sperm concentration, morphology and motility showed increased levels of DNA damage ${ }^{1}$. Significant relationship between SCSA and basic semen parameters ${ }^{2}$ and between sperm head morphology and SCSA were previously reported ${ }^{24}$. It seems that higher values of DFI and HDS reflect more developmental and/or environmental problems which have impact on semen quality. 


\section{ABBREVIATIONS}

AO, Acridine Orange; ART, Assisted reproductive technologies; CL, Chemiluminescence; DFI, DNA fragmentation index; DMSO, Dimethylsulphoxide; DNA, Deoxyribonucleic acid; HDS, High DNA stainability; NSI, Normozoospermic infertile men; PBS, Phosphate buffered saline; ROS, Reactive oxygen species; SA, Semen abnormalities; SCSA, Sperm Chromatin Structure Assay; RLU, Relative light unit.

\section{ACKNOWLEDGEMENT}

The work was supported by the Internal Grant Agency of the Czech Ministry of Health (Grant project NT11083) and by the Internal Grant of Palacky University Olomouc (LF_2012_016). The authors thank to Lenka Radova, $\mathrm{Ph}$.D. for statistical analyses.

\section{CONFLICT OF INTEREST STATEMENT}

Author's conflict of interest disclosure: The authors stated that there are no conflicts of interest regarding the publication of this article.

\section{REFERENCES}

1. Erenpreiss J, Spano M, Erenpreisa J, Bungum M, Giwercman A. Sperm chromatin structure and male fertility: biological and clinical as pects. Asian J Androl 2006;8:11-29.

2. Rybar R, Markova P, Veznik Z, Faldikova L, Kunetkova M, Zajicova A. Sperm chromatin integrity in young men with no experiences of infertility and men from idiopathic infertility couples. Andrologia 2009;41:141-9.

3. Spano M, Bonde JP, Hjolund HI, Kolstad HA, Cordelli E, Leter G. Sperm chromatin damage impairs human fertility. Fertil Steril 2000;73:43 50.

4. Lin MH, Kuo-Kuang Lee R, Li SH, Lu CH, Sun FJ, Hwu YM. Sperm chromatin structure assay parameters are not related to fertilization rates, embryo quality, and pregnancy rates in in vitro fertilization and intracytoplasmic sperm injection, but might be related to spontaneous abortion rates. Fertil Steril 2008;90:352-9.

5. Marcon L, Boissonneault G. Transient DNA strand breaks during mouse and human spermiogenesis new insights in stage specificity and link to chromatin remodeling. Biol Reprod 2004;70:910-8.

6. Laberge RM, Boissonneault G. On the nature and origin of DNA strand breaks in elongating spermatids. Biol Reprod 2005;73:289-96.

7. Marchiani S, Tamburrino L, Maoggi A, Vannelli GB, Forti G, Baldi E. Characterization of M540 bodies in human semen: evidence that they are apoptotic bodies. Mol Hum Reprod 2007;3:621-31.
8. Donà G, Fiore C, Andrisani A, Ambrosini G, Brunati A, Ragazzi E. Evaluation of correct endogenous reactive oxygen species content for human sperm capacitation and involvement of the NADPH oxidase system. Hum Reprod 2011;26:3264-73. doi: 10.1093/humrep/ der321

9. Agarwal A, Saleh RA, Bedaiwy MA. Role of reactive oxygen species in the pathophysiology of human reproduction. Fertil Steril 2003;79:829-43.

10. Aitken RJ, Harkiss D, Buckingham D. Relationship between ironcatalysed lipid peroxidation potential and human sperm function. J Reprod Fertil 1993;98:257-65.

11. Aziz N, Saleh RA, Sharma RK, Lewis-Jones I, Esfandiari N, Thomas AJ $\mathrm{Jr}$, Agarwal A. Novel association between sperm reactive oxygen species production, sperm morphological defects, and the sperm deformity index. Fertil Steril 2004;81:349-54.

12. Makker K, Agarwal A, Sharma R. Oxidative stress \& male infertility. Indian J Med Res 2009;129:357-67.

13. Oborna I, Wojewodka G, De Sanctis JB, Fingerova H, Svobodova M, Brezinova J. Increased lipid peroxidation and abnormal fatty acid profiles in seminal and blood plasma of normozoospermic males from infertile couples. Hum Reprod 2010;25:308-16.

14. Oborna I, Malickova K, Fingerova H, Brezinova J, Horka P, Novotny J. A randomized controlled trial of Lycopene treatment on soluble receptor for advanced glycation end products in seminal and blood plasma of normospermic men. Am J Reprod Immunol 2011;66:17984.

15. Aziz N, Novotny J, Oborna I, Fingerova H, Brezinova J, Svobodova M. Comparison of chemiluminescence and flow cytometry in the estimation of reactive oxygen and nitrogen species in human semen. Fertil Steril 2010;94:2604-8.

16. World Health Organization. WHO laboratory manual for the examination and processing of human semen. $5^{\text {th }}$ ed. 2010;Geneva: WHO Press.

17. Fingerova H, Oborna I, Novotny J, Svobodova M, Brezinova J, Radova L. The measurement of reactive oxygen species in human neat semen and in suspended spermatozoa: a comparison. Reprod Biol Endocrinol 2009;7:110 doi:10.1186/1477-7827-7-118

18. Aitken RJ, Krausz C. Oxidative stress, DNA damage and the Y chromosome. Reproduction 2001;122:497-506.

19. Cocuzza M, Sikka SC, Athayde KS, Agarwal A. Clinical relevance of oxidative stress and sperm chromatin damage in male infertility: an evidence based analysis. Int Braz J Urol 2007;33:603-21.

20. Sakkas D, Moffatt O, Manicardi GC, Mariethoz E, Tarozzi N, Bizzaro D. Nature of DNA damage in ejaculated human spermatozoa and the possible involvement of apoptosis. Biol Reprod 2002;66:1061-7.

21. Barratt CL, Aitken RJ, Björndahl L, Carrell DT, de Boer P, Kvist U. Sperm DNA: organization, protection and vulnerability: from basic science to clinical applications-a position report. Hum Reprod 2010;25:824-38.

22. Desai NR, Mahfouz R, Sharma R, Gupta S, Agarwal A. Reactive oxygen species levels are independent of sperm concentration, motility, and abstinence in a normal, healthy, proven fertile man: a longitudinal study. Fertil Steril 2010;94:1541-3.

23. Zini A, Bielecki R, Phang D, Zenzes MT. Correlations between two markers of sperm DNA integrity, DNA denaturation and DNA fragmentation, in fertile and infertile men. Fertil Steril 2001;75:674-7.

24. Zini A, Phillips S, Courchesne A, Boman JM, Baazeem A, Bissonnette F. Sperm head morphology is related to high deoxyribonucleic acid stainability assessed by sperm chromatin structure assay. Fertil Steril 2009;91:2495-500. 